\title{
Excretion of chromium sesquioxide administered as a component of paper to sheep
}

\author{
By J. L. CORBETT, J. F. D. GREENHALGH, I. McDONALD \\ AND E. FLORENCE
}

Rowett Research Institute, Bucksburn, Aberdeen

\section{(Received 14 September 1959)}

It has been shown (Corbett, Greenhalgh \& McDonald, 1958; Corbett, Greenhalgh $\&$ Florence, 1959) that the diurnal variation in the concentration of chromium sesquioxide $\left(\mathrm{Cr}_{2} \mathrm{O}_{3}\right)$ in the faeces of ruminants that have received regular concentrated doses of this marker is due primarily to uneven mixing of the oxide with the contents of the reticulo-rumen and to its passage from this organ in advance of the food residues it is intended to mark. It is unlikely, however, that a better marker substance than $\mathrm{Cr}_{2} \mathrm{O}_{3}$ will be found (Corbett, Greenhalgh, Gwynn \& Walker, 1958).

Various sampling techniques have been suggested to obtain an unbiased estimate of the mean concentration of $\mathrm{Cr}_{2} \mathrm{O}_{3}$ in faeces. Kane, Jacobson \& Moore (1952) proposed that samples of faeces should be obtained from cows, directly from the rectum if necessary, at the time or times when the concentration of $\mathrm{Cr}_{2} \mathrm{O}_{3}$ is found to be close to the mean value for the $24 \mathrm{~h}$ period. This technique is valid only if the pattern of $\mathrm{Cr}_{2} \mathrm{O}_{3}$ excretion is constant from day to day, which will be so only when the conditions of management and the feeding behaviour of the animals are strictly uniform. The time of sampling was studied also by Lambourne (1957), who concluded that, if the marker doses were administered and the faecal samples were taken twice daily at intervals of about 9 and $15 \mathrm{~h}$, the mean marker concentration in the samples would yield an unbiased estimate of the general concentration of marker in the faeces. Raymond \& Minson (1955) described how representative samples of faeces of a group of grazing sheep could be obtained from the sward, and a similar technique has been used with grazing cattle (Corbett \& Greenhalgh, 1960).

Any sampling procedure would be more reliable if the passage of $\mathrm{Cr}_{2} \mathrm{O}_{3}$ through the alimentary tract and its excretion could be made more regular. Balch, Reid \& Stroud ( 1957 ) concluded that $\mathrm{Cr}_{2} \mathrm{O}_{3}$ should be administered to animals at pasture before the main periods of grazing to ensure that the maximum passage of $\mathrm{Cr}_{2} \mathrm{O}_{3}$ from the reticulo-rumen coincided with the maximum passage of dry matter. They also suggested that $\mathrm{Cr}_{2} \mathrm{O}_{3}$ should be given in a form in which it would be carried into the rumen, for example as a 'macaroni', the form suggested by Edin, Kihlén \& Nordfeldt (1944-5). In earlier work Crampton \& Lloyd (195I) found that the digestibility of foodstuffs by sheep could be determined satisfactorily from the concentrations of $\mathrm{Cr}_{2} \mathrm{O}_{3}$ in faeces when the oxide was given in a small quantity of ground food, but not when administered in more concentrated forms. Pigden \& Brisson (I956) and Brisson, Pigden \& Sylvestre (1957) found that $\mathrm{Cr}_{2} \mathrm{O}_{3}$ was excreted more regularly 
when administered six times, rather than once or twice, daily. Frequent dosing, however, is not usually practicable.

It appears that a more regular passage of $\mathrm{Cr}_{2} \mathrm{O}_{3}$ through the gut would be achieved by administering it in a form in which it would be carried into the rumen and then be released from the carrier slowly, so avoiding the formation of a concentration of $\mathrm{Cr}_{2} \mathrm{O}_{3}$ near the reticulo-omasal orifice, such as probably occurs after the dissolution of administered gelatin capsules (Corbett et al. 1959). To this end Pigden \& Brisson ( 1957 ) developed a 'sustained-release pellet' consisting of equal parts $\mathrm{Cr}_{2} \mathrm{O}_{3}$ and plaster of Paris moulded into a cylinder, and we developed a paper incorporating $\mathrm{Cr}_{2} \mathrm{O}_{3}$. A comparison of these methods (Corbett, Greenhalgh \& McDonald, 1958) showed that both gave a more uniform flow of $\mathrm{Cr}_{2} \mathrm{O}_{3}$ through the duodenum of sheep than did the administration of $\mathrm{Cr}_{2} \mathrm{O}_{3}$ powder in gelatin capsules. In addition, $\mathrm{Cr}_{2} \mathrm{O}_{3}$ particles derived from the paper appeared to be associated with organic material in the duodenal contents, probably because the aluminium sulphate added during the making of the paper caused attachment of the $\mathrm{Cr}_{2} \mathrm{O}_{3}$ to the cellulose fibres of the paper.

In the experiment reported here the administration of $\mathrm{Cr}_{2} \mathrm{O}_{3}$ powder in gelatin capsules was compared with the administration of $\mathrm{Cr}_{2} \mathrm{O}_{3}$ incorporated in paper by examining concentrations of $\mathrm{Cr}_{2} \mathrm{O}_{3}$ in faeces. A comparison with the 'sustainedrelease pellet' was abandoned in the early stages of the experiment because it was found that the sheep frequently regurgitated fragments and even whole pellets $(3 \times 1 \mathrm{~cm}$; sp.gr. $2 \cdot 4$ ), thus vitiating the technique. This effect was also observed by Pigden $\&$ Brisson (1957) with sheep but not with cattle. Regurgitation might be avoided if the specific gravity of the pellets could be increased to over $4^{*}$ I (Dewey, Lee $\&$ Marston, I958), which was not attempted.

\section{EXPERIMENTAL}

Preparation of the $\mathrm{Cr}_{2} \mathrm{O}_{3}$-paper. Small samples of several types of $\mathrm{Cr}_{2} \mathrm{O}_{3}$-paper were hand-made for preliminary testing. It was found that paper made from fully bleached sulphite wood-pulp (acid process) retained less $\mathrm{Cr}_{2} \mathrm{O}_{3}$ and also disintegrated more rapidly when incubated in rumen liquor or when inserted by fistula into the rumen of cattle than paper made from Kraft pulp (prepared from wood by an alkali process). Thicker sheets of paper of both types retained more $\mathrm{Cr}_{2} \mathrm{O}_{3}$ and disintegrated more slowly in the rumen than thin sheets.

It was decided that the most satisfactory $\mathrm{Cr}_{2} \mathrm{O}_{3}$-paper would be the one that retained its identity as paper for the longest time in the rumen and held the largest amounts of $\mathrm{Cr}_{2} \mathrm{O}_{3}$ so that the volume of a dose and the amount of cellulose it contained would be as low as possible. Dr F. L. Hudson of the Manchester College of Science and Technology kindly arranged and supervised the manufacture of about $35 \mathrm{lb} \mathrm{Cr}_{2} \mathrm{O}_{3}-$ paper on a machine at the College. To roo parts by weight of Kraft wood-pulp (air-dry basis) were added 75 parts $\mathrm{Cr}_{2} \mathrm{O}_{3}$ and, to improve retention of $\mathrm{Cr}_{2} \mathrm{O}_{3}$, about 2 parts aluminium sulphate ('paper-maker's alum'). The pulp was beaten moderately, to 300-350 degrees Canadian Freeness (Grant, I942), to assist retention of $\mathrm{Cr}_{2} \mathrm{O}_{3}$ and to give additional strength to the resulting sheet, but without causing undue shortening of the cellulose fibres. The pulp was processed into paper of substance weight approxi- 
mately $70 \mathrm{lb}$ Double Crown 480 (i.e. about $170 \mathrm{~g} / \mathrm{m}^{2}$ ). The large addition of $\mathrm{Cr}_{2} \mathrm{O}_{3}$ allowed for wastage in the water drained from the forming sheet. This water was run to waste because the usual practice of recirculation could result in a progressive increase in $\mathrm{Cr}_{2} \mathrm{O}_{3}$ retention.

Approximately $2 \mathrm{~kg}$ of this $\mathrm{Cr}_{2} \mathrm{O}_{3}$-paper were used for the experiment. Twenty-five random samples, taken as strips across the roll of paper and each weighing about $0.2 \mathrm{~g}$, contained a mean of $39.48 \pm 0.14 \% \mathrm{Cr}_{2} \mathrm{O}_{3}$ in the dry matter.

Preparation of $\mathrm{Cr}_{2} \mathrm{O}_{3}$ doses. Half of the paper was cut into pieces about $8 \times 20 \mathrm{~cm}$, weighing exactly the amount calculated to contain $\mathrm{I} \mathrm{g}_{\mathrm{Cr}_{2}} \mathrm{O}_{3}$. The pieces were rolled up and, to facilitate dosing, were put into gelatin capsules $60 \mathrm{~mm}$ long and $15 \mathrm{~mm}$ in diameter. These capsules were used in the paper-sheet treatment $(\mathrm{P})$.

The remainder of the paper was shredded by a machine used for destroying documents into ribbons of about $2 \times 120 \mathrm{~mm}$. The resulting material was mixed and placed in gelatin capsules in amounts calculated to contain $\mathrm{I} \mathrm{Cr}_{2} \mathrm{O}_{3}$, and was used in the shredded-paper treatment (SP). The reasons for shredding the paper were to study the effects of the different physical form on $\mathrm{Cr}_{2} \mathrm{O}_{3}$ excretion, to minimize variations between doses due to undetected variations in the composition of the paper sheet, and to reduce the possibility of the regurgitation and ejection of a paper dose.

For the control treatment $(\mathrm{C})$, machine-made gelatin capsules containing I $\mathrm{g} \mathrm{Cr}_{2} \mathrm{O}_{3}$ in suspension in oil (R. P. Scherer and Co. Ltd, Slough) were used.

Animals and their management. Twelve Blackface sheep were placed in metabolism cages. Each received $250 \mathrm{~g}$ chopped dried grass at $07.00, \mathrm{Ir} .30$ and $19.00 \mathrm{~h}$ daily throughout the experiment and water ad lib.

Each animal received a total of $\mathrm{I}_{\mathrm{Cr}_{2}} \mathrm{O}_{3}$ daily, administered as a single dose by balling gun at $10.00 \mathrm{~h}$. At the beginning of the experiment three sheep were allocated at random to each of four treatments, control (C), paper-sheet (P), shreddedpaper (SP) and 'sustained-release pellet'. The fourth treatment was abandoned after 7 days when it had been found that many pellets were regurgitated, and the three sheep concerned were re-allocated at random, one to each of treatments C, P and SP.

Collection of samples and chemical methods. To determine the time required for the excretion of $\mathrm{Cr}_{2} \mathrm{O}_{3}$ in the faeces to equilibrate with intake, faeces were collected separately from each sheep for consecutive 3 -day periods, nos. I-4, beginning $48 \mathrm{~h}$ after the first administration. Each 3 -day collection was dried to constant weight at $100^{\circ}$ and milled.

The variability of $\mathrm{Cr}_{2} \mathrm{O}_{3}$ content in samples of faeces taken directly from the rectum (grab-samples) at different times of day was studied when all the sheep had received $\mathrm{a} \mathrm{Cr}_{2} \mathrm{O}_{3}$ treatment continuously for at least 2 weeks. During consecutive 3 -day collection periods, A, B, C, and D, a grab-sample was taken once a day from each sheep on each of the 12 days, but at a different time each day. The twelve samples obtained from each sheep provided estimates, which were independent of each other, of the concentration of $\mathrm{Cr}_{2} \mathrm{O}_{3}$ in faeces at the $2 \mathrm{~h}$ intervals from 02.00 to $24.00 \mathrm{~h}$. The order in which, day by day, the samples were obtained was randomly determined for each of four blocks containing one sheep from each treatment.

The concentration of $\mathrm{Cr}_{2} \mathrm{O}_{3}$ in grab-samples is influenced to some extent by the 
size of the sample, so it was important that each should represent a similar proportion of the total daily excretion of dry matter by each sheep. As daily excretions were roughly constant, this aim was achieved by collecting the samples in nickel crucibles of about $70 \mathrm{ml}$ capacity which, when filled, were found to contain an approximately constant quantity of 10-12 g dry matter. These samples were dried to constant weight at $100^{\circ}$ and ashed.

During the last 3 days of the experiment (i.e. collection period D) additional nonrandom grab-samples, each of $40 \mathrm{ml}$, were taken between 10.30 and II.I $5 \mathrm{~h}$ and between 16.30 and $17.15 \mathrm{~h}$. They were pooled for each sheep, dried, weighed and milled.

The concentrations of $\mathrm{Cr}_{2} \mathrm{O}_{3}$ in faeces were expressed per $\mathrm{g}$ organic matter, determined by ashing the dry faeces for $15 \mathrm{~h}$ at $55^{\circ}-57^{\circ} . \mathrm{Cr}_{2} \mathrm{O}_{3}$ in the capsules, complete collections of faeces and grab-samples were determined by the method of Christian \& Coup (1954) which was found to be more rapid and accurate than that of Schürch, Lloyd \& Crampton (1950) used in earlier work.

\section{RESULTS}

Recovery of $\mathrm{Cr}_{2} \mathrm{O}_{3}$. The mean weights of $\mathrm{Cr}_{2} \mathrm{O}_{3}$ administered as the powder in suspension in oil (C), incorporated in a single sheet of paper $(\mathrm{P})$ or in the same weight of paper shredded (SP) were: $0.959 \pm 0.006 \mathrm{~g}, \mathrm{x} \cdot 029 \pm 0.009 \mathrm{~g}$ and $\mathrm{x} .028 \pm 0.006 \mathrm{~g}$,

Table I. Chromium sesquioxide in faeces of individual sheep in two series of successive 3-day periods, as a percentage of the quantity given

\begin{tabular}{|c|c|c|c|c|c|c|c|c|c|c|}
\hline \multirow[b]{2}{*}{ Treatment* } & \multirow{2}{*}{$\begin{array}{c}\text { Sheep } \\
\text { (block } \\
\text { no.) }\end{array}$} & \multicolumn{8}{|c|}{ Period no. $\uparrow$} & \multirow{2}{*}{$\begin{array}{c}\text { Meanfor } \\
\text { periods } \\
\text { A-D }\end{array}$} \\
\hline & & $I$ & 2 & 3 & 4 & A & B & $\mathrm{C}$ & D & \\
\hline C & $\begin{array}{l}\text { I } \\
2 \\
3 \\
4\end{array}$ & $\begin{array}{r}\text { ror } \cdot 8 \\
89 \cdot 7 \\
103 \cdot 9 \\
-\end{array}$ & $\begin{array}{r}99 \cdot 1 \\
104 \cdot 3 \\
98 \cdot 7 \\
-\end{array}$ & $\begin{array}{l}97 \cdot 7 \\
94 \cdot 9 \\
87 \cdot 2 \\
-\end{array}$ & $\begin{array}{r}107.4 \\
102.5 \\
84.5 \\
\end{array}$ & $\begin{array}{r}88 \cdot 3 \\
104 \cdot 3 \\
99 \cdot 1 \\
96 \cdot 6\end{array}$ & $\begin{array}{r}108 \cdot \mathbf{I} \\
91 \cdot 8 \\
88 \cdot 6 \\
105 \cdot 0\end{array}$ & $\begin{array}{r}86 \cdot 2 \\
96 \cdot 6 \\
100 \cdot 1 \\
96 \cdot 6\end{array}$ & $\begin{array}{l}107 \cdot 4 \\
103 \cdot 9 \\
102 \cdot 9 \\
100 \cdot 1\end{array}$ & $\begin{array}{l}97^{*} 5 \\
99^{\circ} 2 \\
97^{\circ} 7 \\
99^{\circ} 6\end{array}$ \\
\hline $\mathbf{P}$ & $\begin{array}{l}I \\
2 \\
3 \\
4\end{array}$ & $\begin{array}{l}96 \cdot 5 \\
78 \cdot 1 \\
75 \cdot 8 \\
-\end{array}$ & $\begin{array}{r}92 \cdot 0 \\
100 \cdot 1 \\
89 \cdot 1 \\
-\end{array}$ & $\begin{array}{r}88.4 \\
93.9 \\
x 07.5 \\
-\end{array}$ & $\begin{array}{r}\mathrm{X} 14.3 \\
103 \cdot 0 \\
97.5 \\
-\end{array}$ & $\begin{array}{c}95^{\circ} \cdot 9 \\
99 \cdot 4 \\
107 \cdot 9 \\
86 \cdot 27\end{array}$ & $\begin{array}{c}\text { I05.9 } \\
98 \cdot 1 \\
94 \cdot 6 \\
89 \cdot 1 \dagger\end{array}$ & $\begin{array}{c}87 \cdot 1 \\
112 \cdot 7 \\
98 \cdot 5 \\
61 \cdot 9\end{array}$ & $\begin{array}{c}\text { 106.9 } \\
88 \cdot 4 \\
99 \cdot 1 \\
84 \cdot 2 \ddagger\end{array}$ & $\begin{array}{c}99 \cdot 0 \\
99 \cdot 6 \\
100 \cdot 0 \\
80 \cdot 47\end{array}$ \\
\hline $\mathrm{SP}$ & $\begin{array}{l}\text { I } \\
2 \\
3 \\
4\end{array}$ & $\begin{array}{l}- \\
84 \cdot 6 \\
82 \cdot 0 \\
87 \cdot 9\end{array}$ & $\begin{array}{r}- \\
109 \cdot 3 \\
103 \cdot 1 \\
91 \cdot 8\end{array}$ & $\begin{array}{r}- \\
96 \cdot 0 \\
107 \cdot 3 \\
96 \cdot 6\end{array}$ & $\begin{array}{r}- \\
93 \cdot 4 \\
97 \cdot 0 \\
103.8\end{array}$ & $\begin{array}{r}97 \cdot 9 \\
92 \cdot 4 \\
101 \cdot 2 \\
100 \cdot 2\end{array}$ & $\begin{array}{r}102.5 \\
94.0 \\
101.5 \\
94.7\end{array}$ & $\begin{array}{r}89 \cdot 5 \\
98 \cdot 6 \\
94 \cdot 0 \\
\text { I03.I }\end{array}$ & $\begin{array}{r}108.3 \\
110.9 \\
85.6 \\
102.5\end{array}$ & $\begin{array}{r}99 \cdot 6 \\
99 \cdot 0 \\
95 \cdot 6 \\
100 \cdot 1\end{array}$ \\
\hline $\begin{aligned} & \text { Period } \\
& \text { means: } \text { C } \\
& \text { P } \\
& \text { SP }\end{aligned}$ & - & $\begin{array}{l}98 \cdot 5 \\
83 \cdot 5 \\
84 \cdot 8\end{array}$ & $\begin{array}{r}100 \cdot 7 \\
93 \cdot 7 \\
101 \cdot 4\end{array}$ & $\begin{array}{r}93.3 \\
96 \cdot 6 \\
100 \cdot 0\end{array}$ & $\begin{array}{r}98 \cdot I \\
104 \cdot 9 \\
98 \cdot I\end{array}$ & $\begin{array}{c}97 \cdot 0 \\
101 \cdot 1 \S \\
97 \cdot 9\end{array}$ & $\begin{array}{l}98 \cdot 4 \\
99 \cdot 4 \S \\
98 \cdot 3\end{array}$ & $\begin{array}{l}94 \cdot 9 \\
99 \cdot 4 \S \\
96 \cdot 3\end{array}$ & $\begin{array}{c}103 \cdot 6 \\
98 \cdot 1 \S \\
101 \cdot 8\end{array}$ & $\begin{array}{l}98 \cdot 5 \\
99 \cdot 5 \S \\
98 \cdot 6\end{array}$ \\
\hline
\end{tabular}

* Sheep dosed with $\mathrm{I} \mathrm{g} \mathrm{Cr}_{2} \mathrm{O}_{3}$ in a gelatin capsule once daily; in $\mathrm{C}$ the $\mathrm{Cr}_{2} \mathrm{O}_{3}$ was in suspension in oil ; in $\mathrm{P}$ it was incorporated in a single sheet of paper about $8 \times 20 \mathrm{~cm}$; in SP it was incorporated in the same weight of paper shredded into strips about $2 \times 120 \mathrm{~mm}$.

$\uparrow$ Period $\mathrm{I}$ began $48 \mathrm{~h}$ after the first dose of $\mathrm{Cr}_{2} \mathrm{O}_{3}$. Period $\mathrm{A}$ began when all the sheep had received the treatments for at least 2 weeks.

$\ddagger$ Excluded from period means (see p. 293).

$\S$ Mean for three sheep. 
respectively. The contents of one $\mathrm{P}$ capsule were regurgitated by sheep ${ }_{4} \mathrm{P}$ (block 4 , paper-sheet treatment) on the penultimate day of the experiment some hours after dosing. The largely intact roll of paper was immediately re-administered and it is unlikely that this circumstance affected the results in any way. None of the C or SP capsules were regurgitated.

The proportion of $\mathrm{Cr}_{2} \mathrm{O}_{3}$ recovered in faeces in each 3-day period is shown in Table I. All sheep ate their ration satisfactorily and the residues left were negligible, with the exception of sheep $4 \mathrm{P}$ whose food intake and faeces output declined gradually during the experiment. The proportion of the administered $\mathrm{Cr}_{2} \mathrm{O}_{3}$ recovered in the faeces of this animal was abnormally low and the values have therefore been excluded from some mean values in Table I. In addition, for periods I-4, the values for the three sheep that originally received the 'sustained-release pellet' treatment were omitted.

The time required for excretion of $\mathrm{Cr}_{2} \mathrm{O}_{3}$ to equilibrate with intake appeared to be about a week for treatments $\mathrm{P}$ and SP and rather less for treatment $\mathrm{C}$. Once equilibrium had been attained the recoveries remained close to $100 \%$ (with the exception of those for sheep ${ }_{4} \mathrm{P}$ ) and did not appear to be influenced by treatment.

Variability in marker excretion. The gradual decline in the quantity of faeces excreted by sheep ${ }_{4} \mathrm{P}$ caused the $\mathrm{Cr}_{2} \mathrm{O}_{3}$ concentration in grab-samples to increase markedly between days $\mathrm{I}$ and $\mathrm{I} 2$ of sampling periods A-D. These concentrations were therefore corrected to the values that would supposedly have been obtained if faecal output had remained constant and similar to that of the other sheep. For this purpose all the faeces were collected every day, and not every 3 days as for the other sheep, and the $\mathrm{Cr}_{2} \mathrm{O}_{3}$ concentration in each collection was determined. The concentration in each day's grab-sample was then divided by the concentration in the total collection for that day and multiplied by 6.02 , this being the mean concentration $(\mathrm{mg} / \mathrm{g}$ organic matter) in the twelve 3 -day collections obtained during the sampling period from the other three sheep on the same treatment, $P$. This method of correction has the theoretical disadvantage of removing any genuine trends in concentration from day to day, but no such trends were found in the results for the other eleven sheep, so it is unlikely to have distorted the results.

The $\mathrm{Cr}_{2} \mathrm{O}_{3}$ concentration in each grab-sample is shown in Fig. $\mathbf{I}$.

The means, ranges, and standard deviations of the concentrations of $\mathrm{Cr}_{2} \mathrm{O}_{3}$ at the twelve different times of day are given for each sheep in Table 2. The variabilities of the concentrations were compared initially by carrying out Bartlett tests (Bartlett, 1937). There were no significant differences in variability between sheep on the same treatment, as tested either by three separate values of $\chi^{2}$, each with three degrees of freedom, or by one value with nine degrees of freedom. In addition to showing that the variability was homogeneous from sheep to sheep, this result indicates that the differences between blocks in the incidence of sample times were of no importance. There were significant differences in variability from treatment to treatment, as tested by a value of $\chi^{2}$ with two degrees of freedom $(P<0.001)$. Since the sheep were randomized to the treatments, and no significant differences were found between sheep within treatments, it is reasonable to attribute this difference in variability 


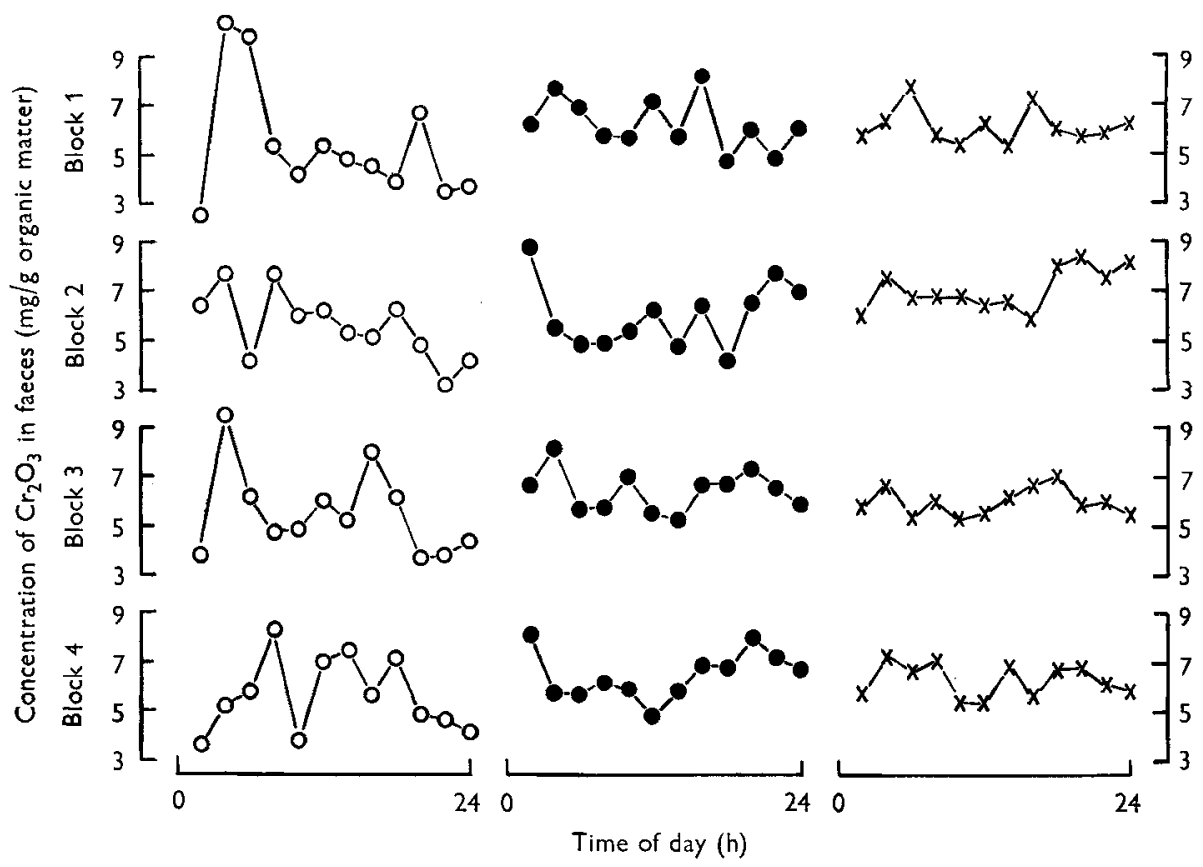

Fig. I. Concentration of chromium sesquioxide in the organic matter of samples of faeces taken once daily from the rectum of each of twelve sheep at different times on 12 consecutive days. The order in which the samples were taken was randomly determined for each block. All sheep received $1 \mathrm{~g} \mathrm{Cr}_{2} \mathrm{O}_{3}$ in a gelatin capsule once daily at $10.00 \mathrm{~h} ; 0-0$, in suspension in oil; $\bullet-\rightarrow$, incorporated in a single sheet of paper about $8 \times 20 \mathrm{~cm} ; \times-\ldots . \times$, incorporated in the same weight of paper shredded into strips about $2 \times 120 \mathrm{~mm}$.

Table 2. Means, ranges and standard deviations of the chromium-sesquioxide concentrations in the organic matter (O.M.) of samples of faeces taken once daily from the rectum of each of twelve sheep at different times on $\mathrm{I} 2$ consecutive days

$\begin{array}{cccc}\text { Sheep (block no.) } & \text { Treatment* C } & \text { Treatment* P } & \text { Treatme } \\ & \text { Mean } \mathrm{Cr}_{2} \mathrm{O}_{3} \text { concentration (mg/g o.M.) } & \\ \text { I } & 5.4 & 6 \cdot 2 & 6 \cdot 1 \\ 2 & 5 \cdot 6 & 6 \cdot 0 & 7 \cdot 0 \\ 3 & 5 \cdot 5 & 6 \cdot 4 & 6 \cdot 0 \\ 4 & 5 \cdot 7 & 6 \cdot 5 & 6 \cdot 3\end{array}$

Corresponding ranges (maximum - minimum values) (mg/g o.M.)

$\begin{array}{llll}\text { I } & 7 \cdot 8 & 3 \cdot 5 & \mathbf{2} \cdot 3 \\ 2 & 4 \cdot 5 & 4 \cdot 7 & \mathbf{2 \cdot 6} \\ 3 & 5 \cdot 8 & 2 \cdot 8 & 1 \cdot 7 \\ 4 & 4 \cdot 9 & 4 \cdot 0 & 1 \cdot 8\end{array}$

Standard deviations (mg/g o.M.)

$\begin{array}{llll}\mathbf{I} & 2 \cdot 4 & \mathbf{I} \cdot \mathrm{I} & 0.7 \\ \mathbf{2} & \mathbf{1} \cdot 4 & \mathrm{I} \cdot 4 & 0.9 \\ 3 & \mathbf{1} \cdot 8 & 0.8 & 0.5 \\ 4 & \mathrm{I} \cdot 6 & \mathrm{I} \cdot \mathrm{I} & 0.7\end{array}$

* Sheep dosed with $\mathrm{I} \mathrm{g} \mathrm{Cr}_{2} \mathrm{O}_{3}$ in a gelatin capsule once daily; in $\mathrm{C}$ the $\mathrm{Cr}_{2} \mathrm{O}_{3}$ was in suspension in oil; in $\mathrm{P}$ it was incorporated in a single sheet of paper about $8 \times 20 \mathrm{~cm}$; in $\mathrm{SP}$ it was incorporated in the same weight of paper shredded into strips about $2 \times 120 \mathrm{~mm}$. 
to the treatments rather than to some other difference between the groups of sheep.

As can be seen from either the ranges or the standard deviations in Table 2, there was much less variability with treatment $\mathrm{SP}$ than with treatment $\mathrm{C}$, and treatment $\mathrm{P}$ was intermediate in variability. On average, the standard deviation was reduced from $\mathrm{C}$ to SP by a factor of about three.

When diurnal trends were looked for, it was found that the mean $\mathrm{Cr}_{2} \mathrm{O}_{3}$ concentrations in the faeces of sheep on treatment $\mathrm{C}$ showed a significant linear trend downwards from 04.00 to $02.00 \mathrm{~h}$ the following day $(P<0.00 \mathrm{I})$. There was no consistent excretion pattern for the sheep on treatment $P$, but the mean values for sheep on treatment SP showed peaks at about 04.00 and $\mathrm{I} 8.00 \mathrm{~h}$ and troughs at about 02.00 and I0.00 h. These showed up as a significant cubic component of variation through the day when $04.00 \mathrm{~h}$ was again taken as the starting point $(P<0.00 \mathrm{I})$.

Table 3. Comparison of the mean concentration of chromium sesquioxide in the organic matter (о.м.) of a 3-day total collection of faeces from each of eleven sheep with mean concentration estimated from the combined samples taken from the rectum at 10.30 and $16.30 h$ on each of the 3 days

\begin{tabular}{|c|c|c|c|c|}
\hline \multirow[b]{2}{*}{ 'Treatment* } & \multirow[b]{2}{*}{$\begin{array}{c}\text { Sheep } \\
\text { (block no.) }\end{array}$} & \multicolumn{3}{|c|}{ Mean $\mathrm{Cr}_{2} \mathrm{O}_{3}$ concentration (mg/g o.M.) } \\
\hline & & $\begin{array}{l}\text { Determined in } \\
3 \text {-day } \\
\text { total collection }\end{array}$ & $\begin{array}{l}\text { Estimated from } \\
\text { combined samples } \\
\text { from rectum }\end{array}$ & Difference \\
\hline \multirow[t]{4}{*}{$\mathrm{C}$} & I & $6 \cdot 40$ & $5 \cdot 60$ & 0.80 \\
\hline & 2 & $6 \cdot 97$ & $6 \cdot 39$ & 0.58 \\
\hline & 3 & $6 \cdot 18$ & $7 \cdot 32$ & $1 \cdot 14$ \\
\hline & 4 & $6 \cdot 67$ & $7 \cdot 02$ & 0.35 \\
\hline \multirow[t]{4}{*}{$\mathbf{P}$} & I & $7 \cdot 31$ & $7 \cdot 3^{\circ}$ & 0.01 \\
\hline & 2 & $6 \cdot 23$ & 5.59 & 0.64 \\
\hline & 3 & $6 \cdot 98$ & $7 \cdot 24$ & 0.26 \\
\hline & 4 & - & - & - \\
\hline \multirow[t]{4}{*}{ SP } & $\mathbf{I}$ & $7 \cdot 26$ & $7 \cdot 22$ & 0.04 \\
\hline & 2 & 5.97 & $6 \cdot 29$ & 0.32 \\
\hline & 3 & $6 \cdot 56$ & $6 \cdot 47$ & 0.09 \\
\hline & 4 & 7.05 & 6.99 & 0.06 \\
\hline
\end{tabular}

* Sheep dosed with $\mathrm{I} ~_{\mathrm{Cr}} \mathrm{O}_{3}$ in a gelatin capsule once daily; in $\mathrm{C}$ the $\mathrm{Cr}_{2} \mathrm{O}_{3}$ was in suspension in oil; in $\mathrm{P}$ it was incorporated in a single sheet of paper about $8 \times 20 \mathrm{~cm}$; in SP it was incorporated in the same weight of paper shredded into strips about $2 \times 120 \mathrm{~mm}$.

$\mathrm{Cr}_{2} \mathrm{O}_{3}$ concentration in bulked non-random grab-samples. No non-random grabsamples were collected from sheep ${ }_{4} \mathrm{P}$. The values obtained from the other eleven sheep in period D are compared in Table 3 with the concentrations in the complete collections of faeces for the same 3-day period. Although the values are limited in number it is clear that the bulked grab-samples from the sheep on treatments $P$ and SP gave a closer estimate of the true mean concentration than did those from the sheep on treatment $\mathrm{C}$. 


\section{DISCUSSION}

In previous experiments diurnal trends in the concentration of $\mathrm{Cr}_{2} \mathrm{O}_{3}$ in faeces have been demonstrated in successive defaecations (e.g. by Kane et al. 1952) or in grab-samples taken at short intervals (e.g. by Brisson et al. 1957) during continuous $24 \mathrm{~h}$ periods, but because the marker concentrations in successive defaecations or grab-samples cannot be considered to be independent of one another the statistical significance of deviations from the mean concentration cannot be determined. The present experiment was designed so that independent estimates of marker concentrations in faeces could be obtained.

Although exact comparison with other results is difficult, because these are almost invariably expressed graphically or by the extreme range in concentration and may be averages over different numbers of animals or days, the variability in the $\mathrm{Cr}_{2} \mathrm{O}_{3}$ excretion of the sheep on treatment $\mathrm{C}$ appeared to be of similar magnitude to that reported for similar situations by other workers. The administration of $\mathrm{Cr}_{2} \mathrm{O}_{3}$ as a component of paper was, however, most successful in reducing variability in excretion even under the conditions of once-daily dosing which, as shown by Hardison, Engel, Linkous, Sweeney \& Graf (1956), Pigden \& Brisson (1956), Balch et al. (1957) and Davis, Byers \& Luber (1958), causes greater variability than more frequent administration. Indeed, the diurnal fluctuations for the SP treatment were no greater than those observed by Elam, Putnam \& Davis (1959) when $\mathrm{Cr}_{3} \mathrm{O}_{3}$ was mixed uniformly into a completely pelleted ration for beef heifers.

It must be recognized that no technique for dosing with $\mathrm{Cr}_{2} \mathrm{O}_{3}$ or other markers can be expected entirely to eliminate fluctuations in excretion. Although intimate mixing with the complete ration will prevent the diluting effect of food ingestion on marker concentration in rumen contents which probably occurs during the intervals between the administration of the discrete doses, there still remains the possibility that food constituents of different digestibilities may become separated in the reticulorumen and be cleared at different rates (Kane et al. 1952). In addition, as suggested by Bloom, Jacobson, Allen, McGilliard \& Homeyer (1957), the absorption of nutrients from the gut may proceed at varying rates during the day. These circumstances would give rise to varying concentrations of marker in faeces even though digesta flowing through the reticulo-omasal orifice contained a constant concentration.

The single daily peak of excretion of $\mathrm{Cr}_{2} \mathrm{O}_{3}$ (at $04.00 \mathrm{~h}$ ) in the sheep on treatment $\mathrm{C}$ was in agreement with previous results (Greenhalgh, 1959) and with those reported by others (Hardison \& Reid, 1953; Hardison et al. 1956; Balch et al. 1957; Davis et al. I958). It seems likely that it was a consequence of the dose given I $8 \mathrm{~h}$ previously. It is more difficult to account for the two peaks daily observed in sheep on treatment SP which cannot be related directly to the single time of dosing. The trend was perhaps governed by the times of feeding or, more likely, by a complex interaction of feeding and dosing times. For example it is possible that the two troughs in $\mathrm{Cr}_{2} \mathrm{O}_{3}$ concentration were caused by a dilution of $\mathrm{Cr}_{2} \mathrm{O}_{3}$ concentration in rumen contents by the food ingested at 07.00 and $19.00 \mathrm{~h}$. The II.30 $\mathrm{h}$ meal would have had less effect because of its proximity to the dosing time. 
The within-sheep variance for $\mathrm{Cr}_{2} \mathrm{O}_{3}$ concentration can be used to estimate the accuracy with which true mean concentration might be estimated from grab-samples. If the concentration in the grab-samples can be assumed to have a normal distribution, the standard error (s.e.) for mean marker concentration estimated from $\boldsymbol{n}$ random grab-samples would be $\sqrt{ }(v / n)$, where $v=$ the variance. The means of the variances for the four sheep on each treatment were $3.34, \mathrm{I} \cdot 23$ and $0.49\left(\mathrm{mg} / \mathrm{g}\right.$ organic matter) ${ }^{2}$ for treatments $\mathrm{C}, \mathrm{P}$ and SP, respectively. From these values it was calculated that if fourteen random grab-samples (e.g. two daily for 7 days) were taken, mean marker concentration would be estimated with S.E. equal to $\pm 8 \cdot 9,4.7$ and $3.0 \%$ for treatments $\mathrm{C}, \mathrm{P}$ and SP, respectively. These figures may be compared with the S.E. of approximately 10 \% for estimates of marker 'population' means derived from twenty to thirty random grab-samples, calculated by Lambourne (1957). They would not be directly applicable to grazing experiments. In grazing animals the magnitude of diurnal fluctuations would be expected to be greater (Hardison \& Reid, I953; Raymond \& Minson, 1955) but this tendency might be offset to some extent by dosing twice daily (Hardison et al. 1956; Pigden \& Brisson, 1956; Balch et al. 1957; Davis et al. 1958) as is usually done in grazing experiments. An additional factor to be taken into account is that non-random, systematic grab-sampling might be more or less accurate than random sampling, depending on the relation of sampling times to any diurnal trends in marker concentration.

The superiority of treatment SP over $\mathrm{P}$ was most probably due to the release of $\mathrm{Cr}_{2} \mathrm{O}_{3}$ from many places in the rumen rather than from one position, and in this respect 'sustained-release pellets' would probably resemble $P$ capsules more closely than SP capsules. Shredding appeared to eliminate any chance of regurgitation of the dose and would avoid difficulties in the preparation of doses from a less uniform batch of paper than that used in the present experiment.

A further major advantage of $\mathrm{Cr}_{2} \mathrm{O}_{3}$-paper is that when faulty administration occurs, and the dose is ejected, it can readily be re-administered without any loss. On the other hand, faulty administration of hand- or machine-made capsules containing $\mathrm{Cr}_{2} \mathrm{O}_{3}$ powder usually results in the capsule being chewed and broken in the animal's mouth and partly ejected, and an unknown proportion of the dose is inevitably lost.

Many preparations of $\mathrm{Cr}_{2} \mathrm{O}_{3}$ contain appreciable amounts of chromate which, besides being poisonous, will result in low apparent recoveries of $\mathrm{Cr}_{2} \mathrm{O}_{3}$ from faeces if it is not determined in the doses. In the paper-making process, however, chromate and other soluble impurities will be washed out. The $\mathrm{Cr}_{2} \mathrm{O}_{3}$ used to make the paper for our experiment contained up to $0.3 \%$ water-soluble impurities, but in an aqueous extract of the paper chromate was hardly detectable.

The major disadvantage of $\mathrm{Cr}_{2} \mathrm{O}_{3}$-paper is that, at present, the doses must be handweighed. Measurement of a dose of paper by area would be unreliable because variations of up to $\pm 5 \%$ in the weight per unit area of paper may be encountered. We have found, however, that two operators can accurately weigh up to 150 doses in an $8 \mathrm{~h}$ day using an aperiodic analytical balance. Before weighing the paper it must be equilibrated with respect to moisture content in the environment of the balance. Subsequent experience suggests that the SP doses can be contained in a roll 
of ordinary paper instead of in the rather costly gelatin capsules and that the cost per dose, before weighing, will then be rather less than for a comparable machine-made capsule.

It is unlikely that the additional few days apparently required for the excretion of $\mathrm{Cr}_{2} \mathrm{O}_{3}$ to equilibrate with intake when $\mathrm{SP}$ (or $\mathrm{P}$ ) rather than $\mathrm{C}$ capsules are used is of any practical importance. A possible disadvantage is that doses that release $\mathrm{Cr}_{2} \mathrm{O}_{3}$ slowly might accumulate in the rumen and, by disintegrating at different rates, cause day-to-day fluctuations in excretion. In our experiment, however, there was no evidence of serious variations between periods in the $\mathrm{Cr}_{2} \mathrm{O}_{3}$ recovered in the 3-day collections, or of trends between days in the concentrations in the grab-samples. Pigden \& Brisson (1957) found that 'sustained-release pellets' took 4 days to break up in the reticulo-rumen, but earlier work (Corbett, Greenhalgh \& MacDonald, 1958) suggests that $\mathrm{Cr}_{2} \mathrm{O}_{3}$-paper disintegrates more rapidly. Also, one sheep that had been dosed with one $\mathrm{P}$ capsule daily for $\mathbf{1 2}$ days was slaughtered $5 \mathrm{~h}$ after a dose at which time only one roll of paper was found, which suggests that the capsule given the previous day had dissolved and that the paper released had disintegrated in less than $29 \mathrm{~h}$.

The work described here has been concerned with the development of a technique for estimating the faecal output of grazing animals. Shredded paper can be used also to determine the digestibility of roughages given indoors by the marker-ratio method (Edin, 1926) since, unlike $\mathrm{Cr}_{2} \mathrm{O}_{3}$ powder, it is in a form suitable for mixing with such foods.

Arrangements are now being made for the large-scale manufacture of $\mathrm{Cr}_{2} \mathrm{O}_{3}$-paper.

\section{SUMMARY}

I. Twelve Blackface sheep receiving $250 \mathrm{~g}$ chopped dried grass at 07.00 , II.30

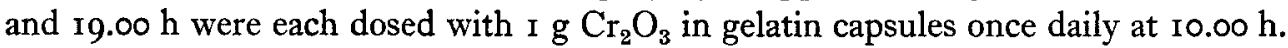
Four received the $\mathrm{Cr}_{2} \mathrm{O}_{3}$ in suspension in oil in machine-made capsules (control treatment $\mathrm{C}$ ); four received a single sheet of paper about $8 \times 20 \mathrm{~cm}$ incorporating the $\mathrm{Cr}_{2} \mathrm{O}_{3}$ (treatment $\mathrm{P}$ ); and four received the same weight of $\mathrm{Cr}_{2} \mathrm{O}_{3}$-paper shredded into strips about $2 \times 120 \mathrm{~mm}$ (treatment SP). A fourth treatment in which the $\mathrm{Cr}_{2} \mathrm{O}_{3}$ was cast with an equal weight of plaster of Paris into a cylinder was abandoned because the sheep regurgitated the casts.

2. The intake and excretion of $\mathrm{Cr}_{2} \mathrm{O}_{3}$ came into equilibrium about a week after dosing began for treatments $\mathrm{P}$ and SP, and rather sooner for treatment C. Subsequently, $\mathrm{Cr}_{2} \mathrm{O}_{3}$ recoveries from faeces remained close to $100 \%$ and were not affected by treatment.

3. During the last 12 days of the experiment faeces were obtained directly from the rectum of each sheep once daily at a different time, determined at random, each day. The twelve samples from each sheep provided estimates, which were independent of one another, of the concentration of $\mathrm{Cr}_{2} \mathrm{O}_{3}$ in the faeces at the 2-hourly intervals from 02.00 to $24.00 \mathrm{~h}$. Variability in concentration was much less for treatment SP than for $\mathrm{C}$, and for treatment $\mathrm{P}$ was intermediate between SP and $\mathrm{C}$. 
4. The advantages of administering $\mathrm{Cr}_{2} \mathrm{O}_{3}$ as the shredded $\mathrm{Cr}_{2} \mathrm{O}_{3}$-paper instead of in the normal way, as powder, are discussed.

We thank Mr A. P. McDonald, Chief Mill Chemist, C. Davidson and Sons Ltd, Bucksburn, for his work in developing the $\mathrm{Cr}_{2} \mathrm{O}_{3}$-paper. One of us (J.F.D.G., now at the Edinburgh School of Agriculture, West Mains Road, Edinburgh) has been in receipt of a Drummond Junior Fellowship for Research in Nutrition.

\section{REFERENCES}

Balch, C. C., Reid, J. T. \& Stroud, J. W. (1957). Brit. F. Nutr. Ir, I84.

Bartlett, M. S. (1937). Proc. roy. Soc. A, 160, 268.

Bloom, S., Jacobson, N. L., Allen, R. S., McGilliard, L. D. \& Homeyer, P. G. (I957). F. Dairy Sci. 40, 240.

Brisson, G. J., Pigden, W. J. \& Sylvestre, P. E. (1957). Canad. F. Anim. Sci. 37, 90.

Christian, K. R. \& Coup, M. R. (1954). N.Z. F. Sci. Tech. A, 36, 328.

Corbett, J. L. \& Greenhalgh, J. F. D. (1960). In Chemical Aspects of the Production and Use of Grass. Monogr. Soc. chem. Ind. no. 9, p. 167.

Corbett, J. L., Greenhalgh, J. F. D. \& Florence, E. (1959). Brit. F. Nutr. 13, 337.

Corbett, J. L., Greenhalgh, J. F. D., Gwynn, P. E. \& Walker, D. (1958). Brit. F. Nutr. I2, 266.

Corbett, J. L., Greenhalgh, J. F. D. \& MacDonald, A. P. (1958). Nature, Lond., r82, Ior 4.

Crampton, E. W. \& Lloyd, L. E. (1951). F. Nutr. 45, 3 I9.

Davis, C. L., Byers, J. H. \& Luber, L. E. (1958). F. Dairy Sci. 4I, 152.

Dewey, D. W., Lee, H. J. \& Marston, H. R. (1958). Nature, Lond., 181, 1367.

Edin, H. (1926). Medd. CentAnst. Försöksv. Fordbr., Stockh., no. $3 \circ 9$.

Edin, H., Kihlén, G. \& Nordfeldt, S. (1944-5). LantbrHögsk. Ann. I2, I66.

Elam, C. J., Putnam, P. A. \& Davis, R. E. (1959). F. Anim. Sci. 18, 718.

Grant, J. (1942). A Laboratory Handbook of Pulp and Paper Manufacture. London: Edward Arnold.

Greenhalgh, J. F. D. (1959). The evaluation and improvement of methods for measuring the herbage consumption of grazing animals. Ph.D. thesis, University of Aberdeen.

Hardison, W. A. \& Reid, J. T. (1953). F. Nutr. 5x, 35.

Hardison, W. A., Engel, R. W., Linkous, W. N., Sweeney, H. C. \& Graf, G. C. (1956). F. Nutr. 58, i .

Kane, E. A., Jacobson, W. C. \& Moore, L. A. (1952). F. Nutr. 47, 263.

Lambourne, L. J. (1957). F. agric. Sci. 48, 415.

Pigden, W. J. \& Brisson, G. J. (1956). Canad. F. agric. Sci. 36, 146.

Pigden, W. J. \& Brisson, G. J. (1957). Canad. F. Anim. Sci. 37, 185.

Raymond, W. F. \& Minson, D. J. (1955). F. Brit. Grassl. Soc. ro, 282.

Schürch, A. F., Lloyd, L. E. \& Crampton, E. W. (1950). F. Nutr. 4r, 629. 